\title{
Delayed Recognition of Geomorphology Papers in The Geological Society of America Bulletin
}

\author{
Evan B. Goldstein*
}

Department of Geological Sciences, University of North Carolina at Chapel Hill, 104 South Rd, Mitchell Hall, Chapel Hill, NC 27599 USA

*Corresponding author: evan.goldstein@unc.edu (email), @ebgoldstein (twitter)

Copyright statement:

Goldstein E.B., Delayed recognition of geomorphology papers in the Geological Society of America Bulletin, Progress in Physical Geography, 41(3) pp. 363-368. Copyright (C) 2017 (The Author). Reprinted by permission of SAGE Publications.

Cite as:

Goldstein, E. B. (2017). Delayed recognition of geomorphology papers in the Geological Society of America Bulletin. Progress in Physical Geography, 41(3), 363-368. https://doi.org/10.1177/0309133317703093

\section{Abstract}

4 geomorphology research. Though geomorphology papers are not uniformly the highest cited papers in the Bulletin, many show 'delayed recognition' - they garner only few citations directly after publication, before suddenly being widely and numerously cited (sometimes decades after publication). I focus here on 1) algorithmically detecting cases of delayed recognition in geomorphology literature from the Bulletin and 2) providing insight into why delayed recognition occurred for these papers. 


\section{Introduction}

The citation record of a paper is one measure of its impact and utility for other scientists.

33 Most papers are typically cited heavily within several years of publication and once the initial

34 window is closed, tend to be cited less frequently (e.g., Costas et al., 2010). This is not true for

35 all papers however - some enjoy 'delayed recognition' in that they remain relatively uncited for

36 long periods of time (even decades) before suddenly being 'rediscovered' and widely and

37 numerously cited (e.g., Garfield, 1980). Finding and analyzing papers with delayed recognition

38 (also referred to as 'sleeping beauties'; Van Raan, 2004) provides insight into a discipline -

39 ideas that may have been 'ahead of their time'. Here I search for papers with delayed recognition

40 that are published in Geological Society of America Bulletin (hereinafter, GSA Bulletin), an early

41 venue for quantitative geomorphology (Morisawa, 1988). Nine of the top 20 papers with delayed

42 recognition in GSA Bulletin concern geomorphology. After presenting these nine 'classic'

43 papers and some general metrics, I discuss possible causes for delayed recognition.

\section{Method of Search and Results}

To look for papers with delayed recognition, I used the Web of Science to download citation histories for the 500 most cited papers published in GSA Bulletin in the 70 year record available (a record of 7,000 'article' documents from 1945 to 2015). This search was performed on August 7, 2016. Note that all 500 'most cited' papers have each been cited more than 100 times. Using these 500 articles I apply the methodology of Ke et al. (2015) to estimate the delay recognition score $(B)$ of each paper. In brief, $B$ is calculated for a given paper by comparing the time series of citations per year to a reference line $(L)$ that connects the year of

53 publication to the maxima in the time series of citations per year (Figure 1). Larger values of $B$ 54 denote a stronger delay recognition signal - the yearly citation maxima occurring far from publication date and with fewer intervening citations. Additionally, a metric of 'awakening time'

$56\left(t_{a}\right)$ can be calculated - defined as the year when a change in yearly citations is observed. This

57 time is calculated by finding the point of maximum distance between the time series of citations per year and the reference line ( $L$; Figure 1$)$. These metrics are parameter free and do not rely on

59 arbitrary, 'tuned' or discipline specific rules. Interested readers are encouraged to seek further 60 details in Ke et al. (2015). 


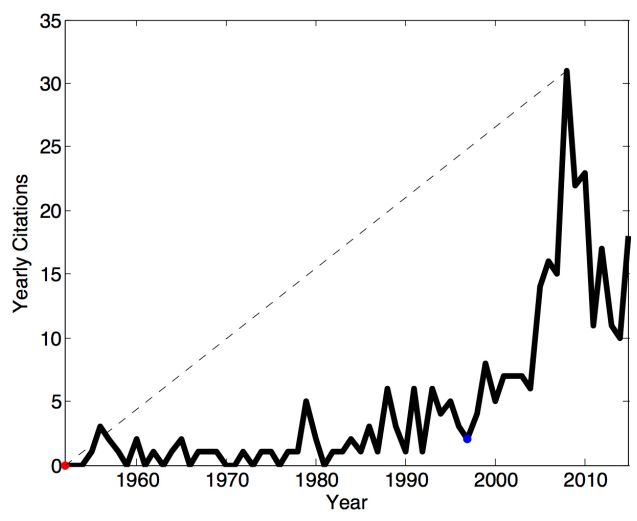

Figure 1: Definition sketch showing citation time series for Strahler (1952a; black line) with the date of publication (red dot). The reference line (L; dotted) is used to calculate the delayed recognition score $(B)$. The awakening time ( $t_{a}$; blue dot) is the point along the citation time series that is furthest from the L. Based on the work of Ke et al. (2015).

71

Of the top 20 delayed recognition articles from GSA Bulletin, nine are geomorphology papers (Table 1). For each of the delayed recognition papers represented in Table 1, the year of peak citation occurs 23-70 years after publication. It is relevant to note that the year of peak citation is post-2000 for all nine papers, and for four papers the peak citation year is 2015 (Horton, 1945; King, 1953; Schumm 1956; Strahler, 1952b), the last year of this analysis. These four papers still show increasing citation rate with time and their true citation peaks may be in the future, which speaks to the continued relevance of these works. Note that the papers in Table 1 did not remain entirely uncited prior to their citation peak, but show a pronounced lack of

81 citations directly after publication relative to their recent citation rates (Figure 2).

82

83

84

85

\begin{tabular}{|c|c|c|c|c|c|c|}
\hline Rank & Title & Authors & Pub Yr & Peak Cit. Yr & B & $\mathrm{t}_{\mathrm{a}}$ \\
\hline 1 & DYNAMIC BASIS OF GEOMORPHOLOGY & STRAHLER, AN & 1952 & 2008 & 384 & 1997 \\
\hline 2 & $\begin{array}{l}\text { HYPSOMETRIC (AREA-ALTITUDE) ANALYSIS OF EROSIONAL } \\
\text { TOPOGRAPHY }\end{array}$ & STRAHLER, AN & 1952 & 2015 & 353 & 2001 \\
\hline 3 & $\begin{array}{l}\text { EROSIONAL DEVELOPMENT OF STREAMS AND THEIR } \\
\text { DRAINAGE BASINS - HYDROPHYSICAL APPROACH TO } \\
\text { QUANTITATIVE MORPHOLOGY }\end{array}$ & HORTON, RE & 1945 & 2015 & 344 & \\
\hline 4 & CONCEPT OF THE GRADED RIVER & MACKIN, JH & 1948 & 2008 & 220 & 1993 \\
\hline & $\begin{array}{l}\text { CLASSIFICATION OF PATTERNED GROUND AND REVIEW OF } \\
\text { SUGGESTED ORIGINS }\end{array}$ & $\begin{array}{l}\text { WASHBURN, } \\
\text { AL }\end{array}$ & 1956 & 2003 & 180 & 2000 \\
\hline 7 & $\begin{array}{l}\text { EVOLUTION OF DRAINAGE SYSTEMS AND SLOPES IN } \\
\text { BADLANDS AT PERTH-AMBOY, NEW-JERSEY }\end{array}$ & SCHUMM, SA & 1956 & 2015 & 179 & 2003 \\
\hline 13 & RIVER MEANDERS & $\begin{array}{l}\text { LEOPOLD, LB; } \\
\text { WOLMAN, MG }\end{array}$ & 1960 & 2012 & 107 & 2001 \\
\hline 15 & CANONS OF LANDSCAPE EVOLUTION & KING, LC & 1953 & 2015 & 103 & 200 \\
\hline 16 & CHANNEL CHANGES IN BADLANDS & $\begin{array}{l}\text { HOWARD, AD; } \\
\text { KERBY, G }\end{array}$ & 1983 & 2006 & 102 & 199 \\
\hline
\end{tabular}

Table 1: Nine geomorphology papers with a high delayed recognition score (B) in GSA Bulletin (1945-2016). Publication year, the year of maximum citations, and the awakening time $\left(t_{a}\right)$ are also listed. 

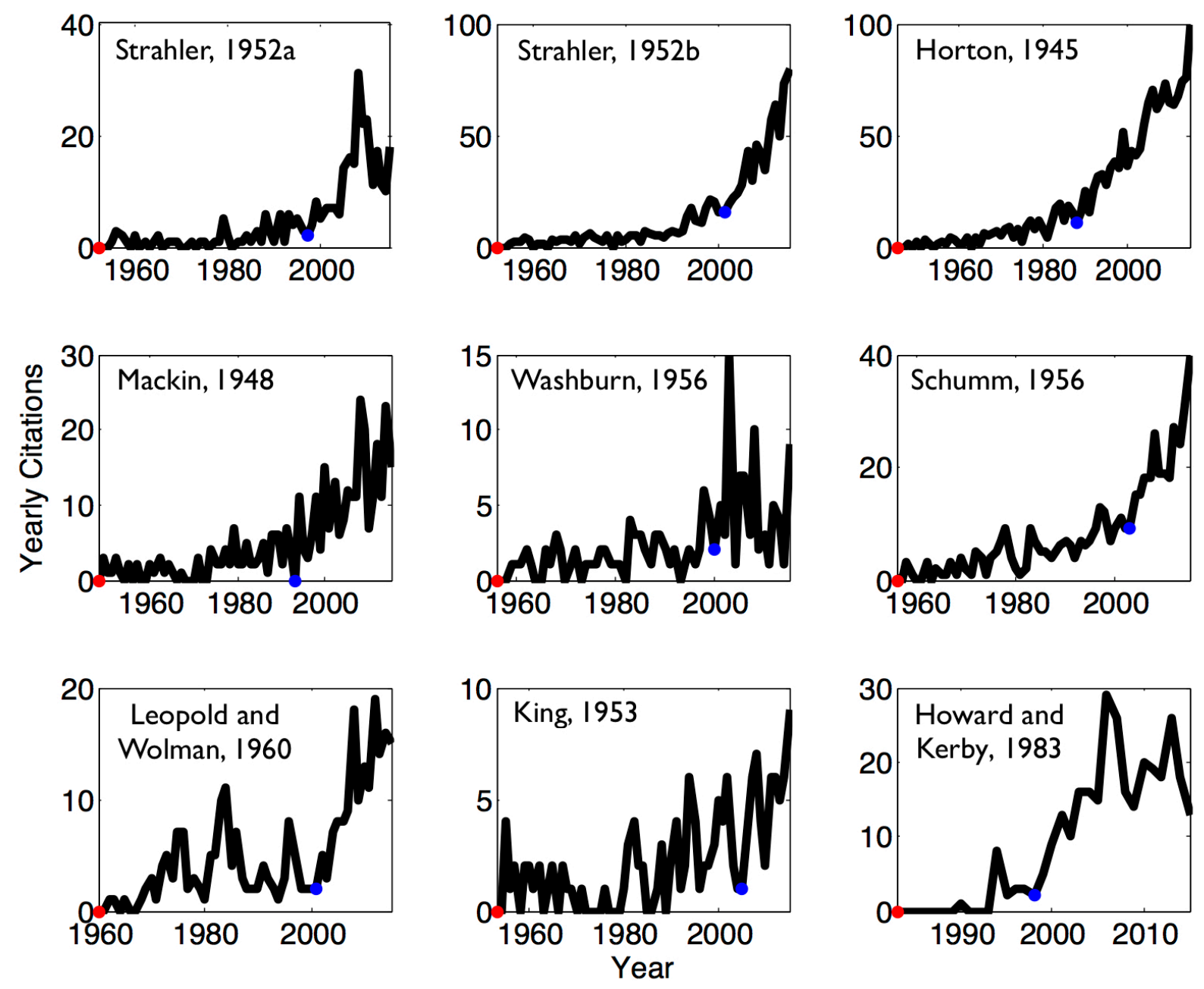

87 Figure 2: Yearly citation time series for the 9 papers in Table 1. Red dots indicate the date of

88 publication. Blue dots indicate the awakening time $\left(t_{a}\right)$. Note the difference in $X$ and $Y$ axis on 89 each panel.

91 III. Discussion and Interpretations

92 These nine geomorphology papers with delayed recognition are not uniformly the most

93 cited of GSA Bulletin articles. The papers in Table 1 range from the $2^{\text {nd }}$ most cited paper in GSA

94 Bulletin (Horton, 1945) to the $300^{\text {th }}$ most cited (King, 1953). Only three of the 20 most cited

95 GSA Bulletin articles are geomorphology. This quantitatively reinforces the fact that GSA

96 Bulletin is a general geoscience journal - which makes the emergence of the nine articles in

97 Table 1 anomalous. As others have suggested before, geomorphology might be prone to generate

98 papers with delayed gratification as a result of the increase in quantitative geomorphology

99 research in the past 20 years, aided by new tools and techniques (e.g., Church 2010; Wohl et al., 
2016). It is clear from looking at the awakening time for all nine articles, which all fall within the range of 1988-2005, that there was a collective explosion of geomorphology research around this time. Intensive research in geomorphology also coincided with the adoption of the Internet data from the World Bank on Internet users suggests that $>50 \%$ of the US, Canada and UK population were internet users by 2002 (http://data.worldbank.org/indicator/IT.NET.USER.P2, accessed on March 6, 2017). The development and use of online academic search tools may have generally played a role in the increasing citations of older literature.

The importance of many of the papers in Table 1 has not gone unnoticed, and retrospective pieces have been written about nearly all of the papers. Morisawa (1988) discussed the importance of early quantitative geomorphology research in GSA Bulletin, specifically focusing on Horton (1945), Mackin (1948) and Strahler (1952a). Three papers from Table 1 have been chronicled in 'Classics Revisited' previously — Chorley (2000) on Mackin (1948), Ollier (1995) on King (1953), and Chorley (1995) on Horton (1945). Additionally, King (1953) is the subject of a retrospective by Twidale (2003), and Rhoads (2006) uses Strahler (1952a) as a lens for examining the philosophy of geomorphology. Even Strahler (1992) wrote in these pages on the historic narrative of his research program, which encompasses the two GSA Bulletin papers.

The specific reason why recognition has been delayed may be aided by examining the record of citations to each paper (what papers cited the delayed work) and also co-citations instances where the paper with delayed recognition and another work are both cited in a third paper. Papers that are co-cited with the delayed paper may provide insight into why a given delayed paper was recognized. Furthermore, co-cited papers that were published around the awakening time, $t_{a}$ also might be clues as to why a specific paper was 'awakened'. All cocitation analysis was performed with Web of Science data, the R programming language (R Core Team, 2016), and the R package bibliometrix (Aria and Cuccurullo, 2016).

It is likely that Washburn (1956) became highly cited as a result of the burst in activity surrounding patterned ground in the early 2000s — notable examples are Kessler et al. (2001) then Kessler and Werner (2003) who developed a self-organized model of patterned ground formation. Mackin (1948) has been valuable for a range of people and subsequent increases in citations to his work from the 1980s onward have been found from stratigraphy papers to landscape evolution papers to tectonic geomorphology works. Strahler (1952b), Horton (1945), and Schumm (1956) all show awakening times around the boom in research focused on tectonic 
131 geomorphology, bedrock rivers, and the modeling of landscape evolution. Horton (1945) is also 132 extensively cited with works regarding the fractal nature of river basins (e.g., Rodríguez-Iturbe 133 and Rinaldo, 2001) and channel initiation studies (e.g., Montgomery and Dietrich, 1992). The

134 acquisition of high resolution topography and the personal computer revolution (which enabled 135 the analysis of high resolution topography and various computer models) no doubt contribute to 136 the interest in these landscape-scale research topics. For instance, Strahler (1952b) is often co137 cited with Willgoose and Hancock (1998), a paper published around the awakening time of 138 Strahler (1952b) that works to extend the utility of the hyposmetric curve using a landscape 139 evolution model.

$140 \quad$ Howard and Kerby (1983) gives the clearest and most explainable trend in this dataset. The 141 citation time series to this paper (Figure 1) shows a prominent uptick in citations in the late 142 1990s and early 2000s as a result in the explosion of interest in bedrock channels. Co-citations 143 are dominated by bedrock channel literature dating from this time.

144 The awakening of some delayed papers is less clear - for example, I can find no reason 145 that Strahler (1952a), which has the highest $B$ value, became highly cited for a period of time. A 146 book was published in 2008 (Burt et al., 2008) resulting in 8 citations to Strahler (1952a), but 147 even without this book there is still a burst of citations. One plausible answer is that Strahler 148 (1952a) is easy to return to - it clearly lays out a quantitative framework for the study of 149 geomorphology (Morisawa, 1988). As a result, any new tool and technique can be brought to 150 bear on these fundamental ideas and questions.

151 King (1953) is perhaps the outlier in these nine works. King's paper was notably 152 qualitative, and even though two of King's 'Canons' are meant to spark quantitative and process 153 based studies (Canon 49 and 50 on page 750; Twidale, 2003), as Ollier (1995) points out, he 154 spoke warily of the mathematical treatment of geomorphology (King, 1953; p.746-747).

155 The geomorphology papers in Table 1 can be compared to delayed recognition in other 156 disciplines. Redner (2005) gives examples of delayed recognition from the physics literature, 157 noting that papers with delayed recognition from the American Physics Society database occur 158 because of upsurges in interest regarding specific topics (e.g., Quantum Information) or novel 159 measurement techniques (e.g., thin film transition metal oxides). Recent work by Ke et al., 160 (2015) presented the most extreme examples of delayed recognition found among 22 million 161 articles (the Web of Science and the American Physical Society records). None of these articles 
162 were from the geoscience literature, and most came from physics and chemistry. The $B$ values of 163 the papers from GSA Bulletin $(B=384$ to $B=209)$ are 1-2 orders of magnitudes lower in $B$ score

164 than the fifteen most 'delayed' papers isolated by Ke et al. (2015), which vary from $B=11,600$ to $165 B=2,184$. Among many reasons for this disparity is the smaller size of the geoscience

166 community, or perhaps the geoscience publication record may not be as large or diverse as other 167 disciplines.

168 The papers in Table 1 serve as a reminder — in an age of exponentially increasing 169 publications (Bornmann and Mutz, 2015) — of the value in searching through older literature 170 during literature reviews (e.g., Pautasso, 2013), a task aided by the advent of online search tools.

171 Ideas from older literature may now be testable or actionable because of new observation, new

172 theory, or recent technological advances. Papers with delayed recognition remind us that good 173 ideas might still be lying dormant in older literature.

\section{Acknowledgement}

I thank E. Janke, E. Lazarus and P. Limber for helpful discussions. I also thank the two anonymous reviewers, Editor David R. Butler, and Managing Editor Nicholas J. Clifford for comments on this work.

\section{Declaration of conflicting interests}

The author declared no potential conflicts of interest with respect to the research, authorship

\section{Funding}

The author received no financial support for the research, authorship and/or publication of this article.

\section{References}

Aria M and Cuccurullo C (2016) bibliometrix: A R tool for comprehensive bibliometric analysis of scientific literature. http://www.bibliometrix.org . (Accessed January 2017).

Bornmann L and Mutz R (2015) Growth rates of modern science: A bibliometric analysis based on the number of publications and cited references. Journal of the Association for Information Science and Technology 66(11): 2215-2222.

Burt TP, Chorley RJ, Brunsden D, Cox NJ, and Goudie AS (2008) The History of the Study of Landforms Volume 4: Quaternary and Recent Processes and Forms (1890-1965) and the MidCentury Revolutions. London: Geological Society.

Chorley RJ (2000) Classics in Physical Geography revisited. Progress in Physical Geography 24(4): 563-578. 
Chorley RJ (1995) Classics in Physical Geography revisited, Progress in Physical Geography 19(4): 533-554.

Church M (2010) The trajectory of geomorphology. Progress in Physical Geography 34(3): 265286.

Costas R, van Leeuwen TN, and van Raan AF (2010) Is scientific literature subject to a 'Sell-By-

Date'? A general methodology to analyze the 'durability' of scientific documents. Journal of the

Garfield E (1980) Premature discovery or delayed recognition-Why. Current Contents (21): 510.

Horton RE (1945) Erosional development of streams and their drainage basins; hydrophysical approach to quantitative morphology. Geological Society of America Bulletin 56(3): 275-370.

Howard AD and Kerby G (1983) Channel changes in badlands. Geological Society of America Bulletin 94(6): 739-752.

Ke Q, Ferrara E, Radicchi F, and Flammini A (2015) Defining and identifying Sleeping Beauties in science. Proceedings of the National Academy of Sciences 112(24): 7426-7431.

Kessler MA, Murray AB, Werner BT, and Hallet B (2001) A model for sorted circles as selforganized patterns. Journal of Geophysical Research 106(B7): 13,287-13,306.

Kessler MA and Werner BT (2003) Self-organization of sorted patterned ground. Science 299(5605): 380-383.

King LC (1953) Canons of landscape evolution. Geological Society of America Bulletin 64(7): 721-752.

Leopold LB and Wolman MG (1960) River meanders. Geological Society of America Bulletin 71(6): 769-793.

Mackin JH (1948) Concept of the graded river. Geological Society of America Bulletin 59(5): 463-512.

Montgomery DR and Dietrich WE (1992) Channel initiation and the problem of landscape scale. Science 255(5046): 826-830.

Morisawa M (1988) The Geological Society of America Bulletin and the development of quantitative geomorphology. Geological Society of America Bulletin 100(7): 1016-1022.

Ollier C (1995) Classics in Physical Geography revisited. Progress in Physical Geography 19(3): 371-377. 
Pautasso M (2013) Ten simple rules for writing a literature review. PLoS Comput Biol 9(7): e1003149.

R Core Team (2016) R: A Language and Environment for Statistical Computing, R Foundation for Statistical Computing. Vienna, Austria. https://www.R-project.org/ (Accessed January 2017).

Redner S (2005) Citation statistics from 110 years of physical review. Physics Today 58(6): 4954 .

Rhoads BL (2006) The dynamic basis of geomorphology reenvisioned. Annals of the Association of American Geographers 96(1): 14-30.

Rodríguez-Iturbe I and Rinaldo A (2001) Fractal river basins: chance and self-organization. Cambridge University Press. New York, NY.

Schumm SA (1956) Evolution of drainage systems and slopes in badlands at Perth Amboy, New Jersey. Geological Society of America Bulletin 67(5): 597-646.

Strahler AN (1992) Quantitative/dynamic geomorphology at Columbia 1945-60: a retrospective. Progress in Physical Geography 16(1): 65-84.

Strahler AN (1952a) Dynamic basis of geomorphology. Geological Society of America Bulletin 63(9): 923-938.

Strahler AN (1952b) Hypsometric (area-altitude) analysis of erosional topography. Geological Society of America Bulletin 63(11): 1117-1142.

Twidale CR (2003) "Canons" revisited and reviewed: Lester King's views of landscape evolution considered 50 years later. Geological Society of America Bulletin 115(10): 115-1172.

Van Raan AF (2004) Sleeping beauties in science. Scientometrics 59(3): 467-472.

Washburn AL (1956) Classification of patterned ground and review of suggested origins. Geological Society of America Bulletin 67(7): 823-866.

Willgoose G and Hancock G (1998) Revisiting the hypsometric curve as an indicator of form and process in transport-limited catchment. Earth Surface Processes and Landforms 23(7): 611623.

Wohl E, Bierman PR, and Montgomery DR (2016) Earth's dynamic surface: A perspective on the past 50 years in geomorphology. Geological Society of America Special Papers 523, SPE523-01. 